\title{
Change of the editorial board
}

\author{
P. Gascon
}

Received: 16 January 2015/ Accepted: 22 January 2015/Published online: 30 January 2015

(c) Federación de Sociedades Españolas de Oncología (FESEO) 2015

The New Year has brought a renovated editorial team to the Journal of Clinical and Translational Oncology.

At the end of last year the Steering Committee of FESEO has appointed me as new Editor-in-Chief of the Journal, the successor to Dr. Andrés Cervantes and Dr. Rosario Perona to whom heartfelt thanks are due for their precious work.

I am honoured to take the leadership of the Journal, which is a great challenge and a big responsibility.

I have been following CTO for the last years and I can say that the Journal we have now inherited is a much better one that the one I recall many years ago.

Overall, 2014 has been a successful year, papers submissions have been over 1,000 and the rejection rate worked up to $80 \%$. Another noteworthy feature of 2014 was the continuing improvement in publication times while maintaining high standards which lead a significant increase of citations that have continuously growing.

From the pages of this Journal, I want to thank the past Editors, thanks to their efforts CTO has become a scientific journal of international reference in Oncology. I also want to thank the Publisher, Springer, for the support provided throughout the last years which allowed the Journal to achieve these good results.

Although, the challenges ahead are many, there are some very relevant for the continuous success and future of the Journal. Rigorous selection of the manuscripts received by the Editorial office will continue to be enforced and we shall have to be rigorous and maintain the current high

P. Gascon $(\bowtie)$

Division Medical Oncology, Department of Hematology-

Oncology (ICMHO), Hospital Clinic, Barcelona, Spain

e-mail: gascon@clinic.ub.es rejection rate. However, more important, we shall strive to be as fair as possible.

The journal is the official publication of FESEO, the organization that represents five Spanish oncology Societies: ASEICA, SEHOP, SEOM, SEOQ and SEOR, this is then the natural home of most medical and radiotherapeutic oncologists, surgeons, pediatricians and cancer researchers.

We hope that the results achieved by CTO, which is now placed between the ten best Spanish scientific journals, will encourage the members of the Societies to submit their works for publication.

I would like also to mention that to increase the impact and worldwide visibility of CTO, electronic contents are made available through the online platform http://www. link.springer.com which provides electronic access to more than 2.750 scientific journals, over 89.000 eBooks, more than 1.500 book series and about 250 reference Works. Abstracts of published articles are freely accessible online; full-text articles are available to researches and institutions with an electronic subscription.

For all of these reasons we would welcome and encourage physicians and researches from Spain and worldwide to consider CTO for submitting their scientific communications. I can assure that we are a team, full of energy and enthusiasm that has accepted this commitment to bring the Journal of Clinical and Translational Oncology to a higher level of scientific excellence and fairness, a task for which we all can feel very proud at the end of the day.

Professor Pere Gascon, Editor-in-Chief. 